\title{
ANALISIS TINGKAT KESEHATAN BANK UM UM SYARIAH DAN UNIT USAHA SYARIAH DENGAN METODE CAMELS DAN RGEC
}

\author{
L otus M ega F ortrania \\ Ulfi K artika Oktaviana \\ Fakultas Ekonomi UIN Maulana Malik Ibrahim Malang \\ Jalan Gajayana No.50 Malang
}

Abstract

Banking should al ways be assessed health to stay fit in serving the customers, the Bank that classified unhealthy can inflict the bank institution itself and of the others, namely the customers of the bank. To assess a health bank can be viewed from various aspects of assessment, this research aimed to determine whether the bank is in a very healthy, heal thy, heal thy enough, less heal thy or unheal thy. There were several methods that can be used to assess or analyze the heal th of the banking, namelyCAMEL, CAMELS and RGEC. This research was a quantitative research, with descriptive approach. The data used was secondary data on 34 banking companiesconsisted of 11 companies of Syaria public banks and 23 companies of Syaria business units. Analysis conducted in thisstudy was to usethecalculation of financial ratios that have been set by the financial services authority. The results showed that the health level of Syaria public Bank and Syaria Business Unit with using CAMELS method and RGEC showed health predicate of the bank in accordancewith thestandards set by Bank Indonesia, for the period 2011 can be concluded that the Syaria public Banks and Sharia Business Unit of composite rankings "HEALT", the period of 2012 with theconclusi on of compositerating "HEALT", and for the period of 2013 with the conclusion of composite rating "HEALT". RGEC method can be said to be better than in the two previous methods, namely CAMELS and CAMEL, through RGEC, BI (Bank Indonesia) wanted banks to beableto identify problems early, performed theappropriateand faster follow- 
up improvements, and implemented Good CorporateGovernance (GCG) and better risk management so banks will bemore resilient in theface of crisis.

Keywords: Bank Health, CAMELS and RGEC

\section{PE NDAHUL UAN}

Sistem ekonomi dunia saat ini di dominasi oleh segelintir pemilik modal dan para kapitalis yang mempunyai pengaruh cukup besar dalam pergerakan roda perekomian dunia yang telah banyak menimbulkan korban sehingga keberadaan bank syariah ini diharapkan mampu untuk memberikan solusi atas keadaan tersebut. Hingga tahun 1998 hanya terdapat satu bank umum syariah dan 78 bank perkreditas rakyat syariah yang telah beroperasi. Tahun 1998 terdapat perubahan undangundang baru yaitu UU No. 10 Tahun 1998 tentang perubahan UU No. 7 Tahun 1992 tentang perbankan.

Berdasarkan data statistik perbankan syariah yang dikeluarkan oleh bank Indonesia mencatat bahwa industri perbankan syariah di Indonesia mengalami perkembangan positif terutama bank umum syariah (BUS), pada tahun 2009 jumlah BUS berjumlah 6 bank dan menjadi 11 bank pada tahun 2010 dan bertahan hingga saat ini. Unit usaha syariah (UUS) yang terdaftar hingga 2013 lalu adalah 23 UUS.

Perbankan harus selalu dinilai kesehatannya agar tetap prima dalam melayani para nasabahnya (Permana, 2012:15) Bank yang tergolong tidak sehat dapat merugikan lembaga bank itu sendiri dan tentu nya orang lain yaitu para nasabah bank tersebut. Untuk menilai suatu kesehatan bank dapat dilihat dari berbagai segi penilaian, ini bertujuan untuk menentukan apakah bank tersebut dalam kondisi yang sangat sehat, sehat, cukup sehat, kurang sehat atau tidak sehat. Terdapat beberapa metode yang dapat digunakan untuk menilai ataupun menganalisis kesehatan perbankan yaitu CAMEL, CAMELS dan RGEC.

Metode atau cara penilaian tersebut kemudian dikenal dengan metode CAMELS yaitu Capital, Asset quality, Management, Earnings, Liquidity, dan Sensitivity to Market Risk. Kriteria sensitivity to market risk merupakan aspek tambahan dari metode penilaian kesehatan bank yang sebelumnya, yaitu CAMEL. CAMEL berkembang menjadi CAMELS pertama kali pada tanggal 1 Januari 1997 di Amerika. CAMELS berkembang di Indonesia pada akhir tahun 1997 sebagai dampak dari krisis ekonomi dan moneter.

Penilaian kesehatan dengan metode RGEC yang tertuang dalam PeraturanBank Indonesia Nomor 13/1/PBI/2011 tanggal 5 Januari 2011 tentang PenilaianTingkat Kesehatan Bank Umum yaiturisk profil $€$, good corporate governance, earning dan capital.Penilaian kesehatan bank tersebut secara umum telah mengalami perubahan sejak pertama kali diberlakukan pada tahun 1999 (Luluk, 2011), yaitu CAMEL kemudian diubah menjadi CAMELS dan kini Bank Indonesia (BI) 
menetapkan RGEC. Melalui RGEC, BI menginginkan bank mampu mengidentifikasi permasalahan secara lebih dini, melakukan tindak lanjut perbaikan yang sesuai dan lebih cepat, serta menerapkan Good CorporateGovernance(GCG) dan manajemen risiko yang lebih baik sehingga bank lebih tahan dalam menghadapi krisis.

Analisis kesehatan bank telah mengalami perubahan, alat analisis CAMEL dan CAMELS tidak berlakukan kembali dan telah berganti menjadi RGEC tetapi disini akan dijabarkan keseluruhan dari seluruh analisis tersebut untuk mengaplikasikan kesehatan bank yang telah dipraktekkan dengan laporan keuangan yang telah dipublikasikan sekaligus sebagai penambahan ilmu untuk mengetahui bagaimana alur dari penilaian tersebut sehingga dapat diambil manfaatnya.

Tujuan dari penelitian terdahulu yaitu untuk mengetahui tingkat kesehatan bank umum syariah dan unit usaha syariah dengan menggunakan metode CAMELS dan RGEC.

\section{METODE PE NEL ITIAN}

Pada penelitian ini fokus pada perusahaan lembaga keuangan milik pemerintah yang terdaftar di Bank Indonesia pada tahun 2011-2013 dengan mengakses website Bank Indonesia yaitu www.OJK.go.id. Jenis penelitian ini adalah penelitian kuantitatif dengan pendekatan deskriptif. Penelitian ini merupakan suatu kegiatan yang di lakukan secara terencana dan sistematis untuk mendapatkan jawaban pemecahan masalah terhadap fenomena-fenomena tertentu.Penelitian kuantitatif dapat diartikan sebagai metode penelitian yang berlandaskan pada filsafat positivisme, digunakan untuk meneliti pada populasi atau sampel tertentu (Sugiyono 2013:13). Hanya ada satu jenis data yang diambil penulis untuk melengkapi proposal skripsi ini yaitu Data Sekunder. Sumber-sumber data diperoleh dari otoritas jasa keuangan periode 2011-2013 yang berisilaporan kinerja bank dengan menggunakan rasiokeuangan yang meliputi aspek rasio capital adequacy, assets quality, management, earnings, liquidity, dan sensitivity, serta laporan laba rugi bank.Data tersebut merupakan data panel (pool ed data), yaitu gabungan data antar bank (cross section) danruntun waktu (time series). Data sekunder dikumpulkan dengan menggunakan teknik pengumpulan data melalui studi kepustakaan berupajournal, data di Bank Indonesia, text book, dan karyatulis yang berhubungan dengan penelitian ini, sertamengakses website.

\section{HASIL PE M BAHASAN DAN PE NEL ITIAN}

Perkembangan tingkat kesehatan umum syariah dan unit usaha syariah yang dinilai dengan menggunakan metode CAMELS (Capital, Asset, Management, Earning, Liquidity and sensitivity to market risk) mengalami peningkatan dalam perkembangan tingkat kesehatan selama kurun waktu tiga tahun berturut-turut 
yakni dari tahun 2011-2013. Hasil penilaian tingkat kesehatan bank umum syariah dan unit dapat dilihat sebagai berikut:

Tabel 1. PredikatPenilaian B ank U mum Syariah

\begin{tabular}{|c|c|c|c|c|c|}
\hline \multirow{2}{*}{ No } & \multirow{2}{*}{ Nama Bank } & \multirow{2}{*}{ K et } & \multicolumn{3}{|c|}{ Predikat } \\
\hline & & & 2011 & 2012 & 2013 \\
\hline 1 & PT. Bank Syariah Muamalat Indonesia & BUS & Sehat & Sehat & Sehat \\
\hline 2 & PT. Bank Syariah Mandiri & BUS & Sehat & Sehat & Sehat \\
\hline 3 & PT. Bank Mega Indonesia & BUS & Sehat & Sehat & Sehat \\
\hline 4 & PT. Bank Syariah BRI & BUS & Sehat & Sehat & Sehat \\
\hline 5 & PT. Bank Syariah Bukopin & BUS & Sehat & Sehat & Sehat \\
\hline 6 & PT. Bank Syariah Panin & BUS & Sehat & Sehat & Sehat \\
\hline 7 & PT. Bank Vic to ria Syariah & BUS & Sehat & Sehat & Sehat \\
\hline 8 & PT. Bank BCA Syariah & BUS & Sehat & Sehat & Sehat \\
\hline 9 & PT. Bank Jabar dan Banten & BUS & Sehat & Sehat & Sehat \\
\hline 10 & PT. Bank Syariah BNI & BUS & Sehat & Sehat & Sehat \\
\hline 11 & PT. Maybank Indonesia Syariah & BUS & Sehat & Sehat & Sehat \\
\hline
\end{tabular}

Pada data di atas terlihat bahwa perkembangan tingkat kesehatan bank umum syariah dan unit usaha syariah tahun 2011-2013 mengalami peningkatan tingkat kesehatan selama tiga tahun berturut-turut. Jika dilihat pada bank umum syariah selama tiga tahun berturut-turut yakni dari tahun 2010-2012 mendapat predikat sehat.

Pada unit usaha syariah selama tiga tahun berturut-turut yakni dari tahun 20112013 mendapat predikat sehat, karena dari hasil perhitungan analisis CAMELS (Capital, Asset, Management, Earning, Liquidity and sensitivity to market risk) angka yang diperoleh berada pada 81-100.

Perkembangan tingkat kesehatan umum syariah dan unit usaha syariah yang dinilai dengan menggunakan metode RGEC (Risk Profile, Good Corporate Governance, Earning dan Capital) mengalami peningkatan dalam perkembangan tingkat kesehatan selama kurun waktu tiga tahun berturut-turut yakni dari tahun 2011-2013. Hasil penilaian tingkat kesehatan bank umum syariah dan unit dapat dilihat sebagaimana tabel 3 . 
Tabel 2. P redikat Penilaian Tingkat K esehatan U nit Usaha Syariah

\begin{tabular}{lllll}
\hline \multirow{2}{*}{ No } & \multicolumn{1}{c}{ Nama Bank } & \multicolumn{3}{c}{ Predikat } \\
\cline { 3 - 5 } & & $\mathbf{2 0 1 1}$ & $\mathbf{2 0 1 2}$ & $\mathbf{2 0 1 3}$ \\
\hline 1 & PT. Bank Danamon & Sehat & Sehat & Sehat \\
2 & PT. Bank Permata & Sehat & Sehat & Sehat \\
3 & PT. B ank Internasional Indonesia & Sehat & Sehat & Sehat \\
4 & PT. CIMB Niaga & Sehat & Sehat & Sehat \\
5 & PT. Bank DKI & Sehat & Sehat & Sehat \\
6 & BPD. DIY & Sehat & Sehat & Sehat \\
7 & BPD Jateng & Sehat & Sehat & Sehat \\
8 & BPD Jatim & Sehat & Sehat & Sehat \\
9 & BPD Banda Aceh & Sehat & Sehat & Sehat \\
10 & BPD Sumatera Barat & Sehat & Sehat & Sehat \\
11 & BPD Sumatera Utara & Sehat & Sehat & Sehat \\
12 & BPD Riau & Sehat & Sehat & Sehat \\
13 & BPD Sumatera Selatan & Sehat & Sehat & Sehat \\
14 & BPD Kalimantan Selatan & Sehat & Sehat & Sehat \\
15 & BPD Kalimantan Barat & Sehat & Sehat & Sehat \\
16 & BPD Kalimantan Timur & Sehat & Sehat & Sehat \\
17 & BPD Sulawesi Selatan & Sehat & Sehat & Sehat \\
18 & BPD Nusa Tenggara Barat & Sehat & Sehat & Sehat \\
19 & PT. B TN & Sehat & Sehat & Sehat \\
20 & PT. B TPN & Sehat & Sehat & Sehat \\
21 & PT. OCBC NISP & Sehat & Sehat & Sehat \\
22 & PT. Bank Sinar Mas & Sehat & Sehat & Sehat \\
23 & BPD Jambi & Sehat & Sehat & Sehat \\
\hline & & & & \\
& & & &
\end{tabular}

Pada data tabel 3 dapat terlihat bahwa perkembangan tingkat kesehatan bank umum syariah dan unit usaha syariah tahun 2011-2013 mengalami peningkatan tingkat kesehatan selama tiga tahun berturut-turut. Jika dilihat pada bank umum syariah dan unit usaha syariah selama tiga tahun berturut-turut yakni dari tahun 2011-2013 mendapat predikat sehat. 
Tabel 3. PredikatP enilaian B ank U mum Syariah

\begin{tabular}{rlcccc}
\hline \multirow{2}{*}{ No } & \multicolumn{1}{c}{ Nama B ank } & K et & \multicolumn{3}{c}{ Predikat } \\
\cline { 4 - 6 } & & & $\mathbf{2 0 1 1}$ & $\mathbf{2 0 1 2}$ & $\mathbf{2 0 1 3}$ \\
\hline 1 & PT. Bank Syariah Muamalat Indonesia & BUS & Sehat & Sehat & Sehat \\
2 & PT. Bank Syariah Mandiri & BUS & Sehat & Sehat & Sehat \\
3 & PT. Bank Mega Indonesia & BUS & Sehat & Sehat & Sehat \\
4 & PT. Bank Syariah BRI & BUS & Sehat & Sehat & Sehat \\
5 & PT. Bank Syariah Bukopin & BUS & Sehat & Sehat & Sehat \\
6 & PT. Bank Syariah Panin & BUS & Sehat & Sehat & Sehat \\
7 & PT. Bank Victoria Syariah & BUS & Sehat & Sehat & Sehat \\
8 & PT. Bank BCA Syariah & BUS & Sehat & Sehat & Sehat \\
9 & PT. Bank Jabar dan Banten & BUS & Sehat & Sehat & Sehat \\
10 & PT. Bank Syariah BNI & BUS & Sehat & Sehat & Sehat \\
11 & PT. Maybank Indonesia Syariah & BUS & Sehat & Sehat & Sehat \\
\hline
\end{tabular}

\section{KE SIMPULAN DAN SARAN}

Berdasarkan hasil penelitian dan analisis data yang telah dilakukan maka dapat diambil kesimpulan sebagai berikut penilaian Tingkat Kesehatan Bank Umum Syariah dan Unit Usaha Syariah dengan menggunakan metode CAMELS dan RGEC ini menunjukkan predikat kesehatan bank tersebut sesuai dengan standar yang telah ditetapkan oleh Bank Indonesia, Untuk periode 2011 dapat disimpulkan bahw a Bank Umum Syariah dan Unit Usaha Syariah peringkat komposit "SEHAT", periode 2012 dengan kesimpulan peringkat komposit "SEHAT", dan untuk periode 2013 dengan kesimpulan peringkat komposit "SEHAT"Berdasarkan hasil penelitian dan kesimpulan tersebut di atas, maka dapat diajukan beberapa saran sebagai berikut: Sebagai bank umum syariah dan unit usaha syariah hendaknya mampu mempertahankan kesehatan bank pada tahun-tahun berikutnya. Kesehatan bank yang sangat sehat akan meningkatkankepercayaan masyarakat, nasabah, karyaw an pemegang saham, danjuga pihak lainnya. (1) Mempertahankan kesehatan bank untuk tahuntahun berikutnya tidakhanya berfokus pada laporan keuangan, tetapi bank tersebut perlu juga untuk mengembangkan usaha dengan pelayanan yangdiberikan lebih aman, mudah, dan juga cepat. Selain itu, pengaruhnegatif yang signifikan dari perubahan kondisi bank bisnis dan faktor eksternal lainnya hendaknya menjadi tolak ukur dalam menyusunanggaran tahun berikutnya. (2) Banyaknya faktor eksternal perusahaan yang berpengaruh terhadap kinerja keuangan seperti faktor pemerintahan sebaiknya juga lebih diperhatikan untuk meningkatkan kinerja keuangan. (3) Bagi peneliti selanjutnya, disarankan untuk memperluas cakupan penelitian tentang 
Tabel 4. P redikat $P$ enilaian Tingkat $K$ esehatan U nit Usaha Syariah

\begin{tabular}{|c|c|c|c|c|}
\hline \multirow{2}{*}{ No } & \multirow{2}{*}{ N ama B ank } & \multicolumn{3}{|c|}{ Predikat } \\
\hline & & 2011 & 2012 & 2013 \\
\hline 1 & PT. Bank Danamon & Sehat & Sehat & Sehat \\
\hline 2 & PT. Bank Permata & Sehat & Sehat & Sehat \\
\hline 3 & PT. Bank Internasional Indonesia & Sehat & Sehat & Sehat \\
\hline 4 & PT. CIMB Niaga & Sehat & Sehat & Sehat \\
\hline 5 & PT. Bank DKI & Sehat & Sehat & Sehat \\
\hline 6 & BPD. DIY & Sehat & Sehat & S ehat \\
\hline 7 & BPD Jateng & Sehat & Sehat & Sehat \\
\hline 8 & BPD Jatim & Sehat & Sehat & S ehat \\
\hline 9 & BPD Banda Aceh & Sehat & Sehat & Sehat \\
\hline 10 & BPD Sumatera Barat & Sehat & Sehat & Sehat \\
\hline 11 & BPD Sumatera Utara & Sehat & Sehat & Sehat \\
\hline 12 & BPD Riau & Sehat & Sehat & Sehat \\
\hline 13 & BPD Sumatera Selatan & Sehat & Sehat & S ehat \\
\hline 14 & BPD Kalimantan Selatan & Sehat & Sehat & S ehat \\
\hline 15 & BPD Kalimantan Barat & Sehat & Sehat & Sehat \\
\hline 16 & BPD Kalimantan Timur & Sehat & Sehat & S ehat \\
\hline 17 & BPD Sulawesi Se latan & Sehat & Sehat & S ehat \\
\hline 18 & BPD Nusa Tenggara Barat & Sehat & Sehat & Sehat \\
\hline 19 & PT. BTN & Sehat & Sehat & S ehat \\
\hline 20 & PT. BTPN & Sehat & Sehat & Sehat \\
\hline 21 & PT. OCBC NISP & Sehat & Sehat & Sehat \\
\hline 22 & PT. Bank Sinar Mas & Sehat & Sehat & S ehat \\
\hline 23 & BPD Ja mbi & Sehat & Sehat & Sehat \\
\hline
\end{tabular}

penilaian kesehatan bank dengan menggunakan indikator rasio keuangan lainnya pada pengukuran tingkat kesehatan

\section{DAFTAR PUSTAK A}

Abdullah, M.A. 2010. Corporate Governance Perbankan Syariah di Indonesia. Yogyakarta: Ar-Ruzz Media.

Anggraeni, O. 2011. Penilaian TingkatKesehatan Bank dengan Menggunakan Metode Camel pada PT Bank Pembangunan Daerah J awaTengah Tahun 2006-2009. Skripsi. Semarang: Universitas Diponegoro.

Anita. 2009. Analisis Tingkat Kesehatan Bank Perkreditan Rakyat Syariah Pada BPRS Kota Bekasi Berdasarkan Peraturan Bank Indonesia No 9/17/PBI/2007. Skripsi. Jakarta: UIN Syarif. 
Anshori, A.G. 2008. HukumPerbankan Syariah. Bandung: Refika Aditama.

Arum. W.P. 2012. Analisis Perbandingan TingkatKesehatan PT Bank Syari' ah Mandiri Dan PT Bank Mandiri (persero) Tbk. Skripsi. Semarang: IAIN Walisongo.

Ayu, I.D. 2013. Analisis Perbedaan Tingkat Kesehatan Bank Berdasarkan RGEC pada Perusahaan Perbankan Besar dan Kecil. E-Jurnal Akuntansi Universitas Udayana 5.2 (2013):483-496. Denpasar.

Bagus, D. Jurnal-sdm.blogspot.com. 14 Januari 2015.

Bank Indonesia. 2011. BookletPerbankan Indonesia. Vol 8 maret 2011.

Budisantoso, T., dan Sigit, T. 2006. Bank dan Lembaga Keuangan Lain. Edisi kedua. Jakarta: Salemba Empat.

Darmawi, H. 2011. Manajemen Perbankan. Jakarta: Bumi Aksara.

Dyah, N. 2013. Analisis TingkatKesehatan Bankdengan Menggunakan MetodeCAMEL. Skripsi. Malang: Universitas Brawijaya.

Fauziah, Z. 2013. Analisis Kinerja dengan Menggunakan RasioCamel danMetodeAltman (Model Z-Score) pada Perusahaan Perbankan. Skripsi. Jember: UNEJ.

Feramita, T.D. 2013. Analisis Tingkat Kesehatan Bank dengan Menggunakan Metode CAMEL pada PT Bank Central Asia Tbk Cabang A. Rifa'i Palembang. Skripsi. Palembang: Universitas Tridinanti.

Hasan, I. 2004. Analisis Data Penelitian Dengan Statistik. Jakarta: Bumi Aksara.

Irawan, I. 2009. Irwanirawan.wordpress.com. 14 Januari 2015.

Irianto, A. 2006. Statistik Konsep Dasar dan Aplikasinya. Jakarta: Kencana.

Irmayanto, J., dkk. 2009. Bank dan Lembaga Keuangan. Jakarta: Universitas Trisakti.

Jumingan. 2011. Analisis Laporan Keuangan. Jakarta: PT Bumi Aksara.

Kashmir. 2000. Manajemen Perbankan. Jakarta: Rajawali Pers.

Kashmir. 2005. Bank danLembaga Keuangan Lainnya. Jakarta: Rajawali Pers.

Kasmir. 2007. Bank dan Lembaga Keuangan lainnya. Jakarta: PT Rajagrafindo.

Lasta, H.A. 2014. Analisis Tingkat Kesehatan Bank dengan Menggunakan Pendekatan RGEC (Risk Profile, Good CorporateGovernance, Earning, Capital). Administrasi Bisnis, Vol 13 No. 2 Agustus 2014.

Lestari, E.P. 2014. Analisis Penilaian TingkatKesehatan Bank pada PT Bank Muamalat Syariah Tbk. Cabang Denpasar. Denpasar: Unud.

Lestari, V.D. 2009.Analisis Tingkat Kesehatan Bank-Bank Pemerintah dengan Menggunakan Metode Camels dan Analisis Diskriminan Periode 2006-2008. Skripsi. Universitas Gunadarma.

Multiparadigma. Lecture. Ub.ac.id (13 Januari 2015).

Muttaqin, H. 2014. Pustakabakul.blogspot.com. 14 Januari 2015.

Pudjianti, S. 2009. Anal isis KinerjaKeuangan Mengenai TingkatKesehatan BankDengan Menggunakan Metode Camel "(Studi Kasus pada PT Bank Negara Indonesia (Persero) Tbk dan PT. Bank Bukopin Tbk Periode2006-2008). Skripsi. Universitas Gunadarma

Repository.usud.ac.id (13 Januari 2015).

Ruwaida, F. 2011. Analisis LaporanKeuangan untukMenilai TingkatKesehatan Keuangan pada PD BPR Bank Klaten. Yogyakarta.

Said, K. 2012. AnalisisTingkat Kesehatan Bankdengan Menggunakan MetodeCAMEL pada PT Bank Syariah Mandi ri. Skripsi. Makassar: Universitas Hasanudin.

El-Dinar, Vol. 3, No 1, Januari 2015 
Saragih, O.L. 2010. Analisis Camel untuk Menilai Tingkat Kesehatan Bank pada Perusahaan Perbankan yang Terdaftar di Bursa Efek Indonesia Periode 20062008. Skripsi. Medan: Universitas Sumatera Utara.

Subagyo, dkk. 2002. Bankdan Lembaga Keuangan Lainnya. Yogjakarta: STIE YKPN.

Suhardiyah, M. 2011. Analisis CAMEL untuk Menganalisis Tingkat Kesehatan Bank Pada Bank CIMB Niaga. Surabaya: Unipa.

Sulistyanto, S., dan Lidyah, R. 2002. Good Governance"Antaral dealisme dan Kenyataan" . Modus, Vol 14 (1) Februari 2002.

Suseno, B. 2010. IndependentT-tes. Statistikolahdata.com. 15 Januari 2015.

Sutedi, A. 2011. GoodCorporateGovernance. Jakarta: Sinar Grafika.

Suteja, J. 2010. Analisis Kinerja Bank Menggunakan Metode CAMELS untuk Mengukur Tingkat Kesehatan Bank terhadap Pertumbuhan Laba. Jurnal Riset Bisnis dan Manajemen, Vol3 Februari 2010.

Tika, P. 2006. Metodologi Riset Bisnis. Jakarta: Bumi Aksara.

Ulya, N.I. 2014. Analisis Perbandingan Tingkat Kesehatan Bank Syariah dan Bank Konvensional Berdasarkan Risk Profile, Good CorporateGovernance, Earning dan Capital. Skripsi. Yogyakarta: UIN Kalijaga.

Unila.ac.id (14 Januari 2015)

Usman, H., dkk. 1996. Metodologi Penelitian Sosial. Jakarta: Bumi Aksara.

Yanti, L.P.A.I.P. 2014. Analisis Tingkat Kesehatan Bank dengan Menggunakan Metode CAMEL. E-J urnal Bisma Universitas Pendidikan Ganesha. Vol 2 Tahun 2014. Singaraja: Jurusan Manajemen.

Zarkasyi, W. 2008. Good CorporateGovernance. Bandung: Alfa Beta. 